\title{
Fostering the professional capital of teachers in digital capabilities
}

\author{
Valeria Pandolfini \\ Department of Science of Education, University of Genoa, Italy
}

\begin{abstract}
The article focuses on teacher professionalism, taking into account the challenges related to the growing digitizing of teaching and learning processes and educational environments, especially in light of the great challenges posed by COVID-19 in the educational sector. First, the article proposes an evaluative framework based on the Capability Approach to investigate the complex links between education and technologies, and the impacts on teachers' collaborative work. Second, the notion of teachers' professional capital is contextualized in the digital era, and the impact of the diffusion of digital technologies on teachers' collaborative practices is examined. Then, some policy recommendations are provided, focusing on teachers' training programs and the implications of adopting the Capability Approach to tackle such issues. The questions arising refer to the types of capital that have to be developed in the teaching profession, which are linked to the diffusion of digital media in the educational sector, and the means for fostering teachers' capability development.
\end{abstract}

Keywords: Professional capital, teachers, capability, digital school, educational policy

\section{INTRODUCTION}

$\mathrm{R}$ apid digitalization over the past decade has transformed many aspects of work and daily life. Driven by innovation and technological evolution, the digital transformation is reshaping society, in relation to different dimensions, from education, to work, to health. The education and training system is increasingly part of the digital transformation and harnesses its benefits and opportunities. The COVID-19 crisis, which has heavily impacted education and training, has accelerated the change and provided a learning experience [18]. The COVID-19 pandemic has amplified opportunities and challenges from the digital transformation, including in the educational sector[37]. The crisis requires us to rethink how education and training are designed and provided to meet the demands of a rapidly changing and increasingly digital world. At the same time, it requires to critically reflect on the prevailing discourses inthe educational sector during the COVID-19 crisis, in order to examine how much teachers' professionalism is becoming more crucial.

Digital school: reiterating the main public discourses on technological innovation

Technological innovation in education has constituted a major public discourse on educational policies in developed countries and it has been part of a multi-faceted debate on innovation and change in educational systems around the world. ICT has been the guiding instrument employed to revolutionize teaching and learning practices.The underlying assumption was that the use of digital technologies would enable the achievement of a wider purpose: innovation in schooling practices and processes[42].

According to [50], the prevalent discourses regarding educational change and the disruption of old-fashioned practices can be clustered into two categories. The first, regarding digital "re-schooling", refers to the role of digital technology in breaking down barriers between and within institutional settings (time/space; experts/novices; production/consumption; synchronous/asynchronous communications, facilitating new ways of participating/interacting, and allowing participants to "bring in" theirdaily practices. These discourses are implicit in the popular discourse surrounding the "future of education": digital technology is seen as supporting "community collaboration"; "content creation and sharing content"; "innovative education practices and new models for learning"; empowering "learning community members" with a "passionate, personal responsibility for learning." The second category of discourse refers to digital "de-schooling": digital technology is seen as completely usurping the educational institutions. The key concepts include self-determination, selforganization, self-regulation and learner autonomy.Digital education is conceived as supporting open discussion and debate, continuous experimentation and knowledge sharing. The underlying imperative is to change the structures, processes and practices of schools, teachers and students along more high-tech, networked and "innovative" lines [50], thereby "promot[ing] togetherness through the fostering of mutual empathy and understanding" ([14], p. 38). Therefore, the common narrative about change paints a scenario in which digital technologies first deconstruct and then restructure the educational field of practice by substituting, replacing and accompanying offline educational practice with new sociotechnical assemblages ([13], p. 99). This perspective highlights the processual dimension of social and organizational everyday life in schools, focusing on the networks and mutual relationships of the human and nonhuman actors [27].

The COVID-19 crisis put us for the first time in a situation where there was little choice but to use digital technologies to provide education and training [18]. Thus, drawbacks due to the "forced" adoption of technologies and what is entailed in 
the process of change of everyday school work have attracted considerable attention among researchers from different fields, such as education, sociology and psychology [49], [22].

Thearticlefocuses on the relationship between technological innovation and teachers' collaborative work. The multiple dimensions of teachers' professionalism [1], [12] and the notion of teachers' professional capital [23], [28] are discussed, assuming the Capability Approach [33],[51], [54] as the specific evaluative framework. Such perspective is adopted as a lens through which to analyze teachers' professional development and training opportunities, examining the potential risks as well as the opportunities connected to the role of digital technologies in continuing vocational training programs for teachers.

\section{THEORETICAL FRAMEWORK}

Capability for (digital) training: accounting for individual agency and contextual constraints

The Capability Approach is based on the core idea that society should enlarge individual opportunities. It emphasizes the freedom for each member of society to promote and obtain the highest expression of "wellbeing and doing" in terms of quality of life and freedom of choice.

A key concept of the Senian approach refers to functioning, that is, the various things a person may value doing or being [55]. According to such definition, capability is the various combinations of functionings (beings and doings) that the person can achieve. Capability is, thus, a set of vectors of functionings, reflecting the person's freedom to lead one type of life or another, to choose from possible living" [53]. Therefore, capabilities describe the actual possibilities that are open to a person.

A person's capability set relies on his/her entitlements and capability to turn them into valuable functioning [52]. Thus, entitlements shape the basis of the capability set, but are not sufficient to guarantee the development of capabilities. However, the point is that people differ in their ability to convert means (resources or endowments that are instrumental for the achievement of other ends) into valuable opportunities (capabilities) or outcomes (functionings) [53]. In the theoretical framework of the Capability Approach, these interindividual differences are captured by the notion of "conversion factors", i.e., the degree to which a person can transform a resource into a functioning. More specifically, the conversion factors may be personal (e.g. gender, nationality, social status, disabilities, skills, etc.); socio-cultural (e.g. social or religious norms, social hierarchy, sexism, racism); or environmental/institutional (e.g. welfare, educational and training system, labour market, living in a dangerous area, etc.) [48].

We will focus on the role of the training system in fostering individual capabilities, starting by inquiring what are the functions of education and training in contemporary society. The answers to these questions, according to the Capability
Approach, generate several considerations. In addition to the intrinsic value of education and knowledge, whereby education is intrinsically valuable as an end in itself [56], we will focus here on two additional functions of education [39]. First, education can be conceived as a means for achieving wellbeing in other relevant life dimensions; in this sense, the instrumental value of education is clear [10]. Sen's view on education is that it is an "overarching" capability that should expand other capabilities, i.e. acquiring skills, taking advantage of the opportunities that these skills afford, or gaining other intrinsically important capabilities [54]. Nussbaum[33] also highlighted that education is central to developing other capabilities and suggested that education is a "fertile functioning". It is often viewed, like health, as a kind of "fundamental" capability because it is internally instrumental within the realm of wellbeing, i.e., of a person's capability set, and it is key to expanding our own and other people's opportunity sets. Second, education might be interpreted as a personal conversion factor, i.e., an internal characteristic determining one's ability to convert input (means) into output (wellbeing). Thus, education is one of the conditions that influence individuals' opportunities to develop their capabilities. Moreover, education is also related to "external factors" such as social characteristics (public policies, institutions, legal rules, social norms, and so on). Thus, if personal conversion factors involve the "physical condition, literacy, competences etc. that influence how a person is able to convert the characteristics, commodities, infrastructures, and arrangements into a functioning" ([38], p. 279 ), education can be more convincingly considered to be an institutional conversion factor.

Specifically referring to the lifelong learning field, the capability for training could be considered as a part of the broader concept of the capability for learning, i.e., the development of positive freedom in life and work. In other words, the capability for training refers to the possibility for a person to choose, among various training opportunities, training that he/she has reason to value, as well as to achieve this training, or even to refuse any training. Based on such a perspective, the purpose of continuing vocational training policies is not to guarantee functioning, but to ensure the rights and freedoms necessary to achieve training that one has reason to value. The Capability Approach does not seek to guarantee outcomes, but to create the proper social and environmental conditions necessary to develop the real freedom to choose training one has reason to value [26]. Hence, again, the interrelations between individuals and their context must be carefully taken into account.

In addressing technological innovation specifically, it is clear that it is challenging the professional, organizational and micro-political life of schools [13]. The development processes through which individuals can convert ICTs means into real improvements in their quality of life has to be conceived as an expansion of the opportunities of individuals to reach a high level of well-being [15]. In the current 
networked society [9], in which everyday relational and communicative practices are increasingly being shaped by digital media and the Internet has become pervasive in daily life, the ability to use digital technologies to access information and knowledge, as well as to participate in the web society, determines the different levels of capability and freedom of choice of a person. As data on the digital divide show [58], the focus is on how to use ICTs effectively in relation to personal needs and desires. This point refers to the so-called third level of the digital divide, i.e., digital capital, which is seen as the returning social benefits of using the Internet [46]. It is a bridge capital which influences the ways people lookfor information and their motivation and support, and provides the skills to elaborate, process and use such information to improve their life chances. It is strongly interrelated with the other five types of capital: social [11], [44], political [55], economic [7], human [3] and cultural [7]. The opportunities provided by the use of ICTs are the product of the interactions between these five capitals and digital capital, which impact the opportunities to access technologies and the Internet (the first level of the digital divide), the online experience (the second level of the digital divide) and the outcomes and social benefits (the third level of the digital divide, [47]). Relying on the conceptualization of [53], the issue of digital inequalities should therefore be re-modulated to focus primarily on the conditions that, due to the introduction of digital technologies, have prevented the capability development of certain groups of subjects, limiting their relevant functioning, and therefore restricting their freedom and individual autonomy to achieve different combinations of "being and doing".

The teachers' professional capital: a complex set of different elements

According to [23], the professional capital of teachers is a function of the interaction of three components: human capital (the talent of the individual), social capital (the quality of the group), and decisional capital (the development of the expertise and professional judgement of individuals and groups, which enables them to make increasingly effective decisions over time). Let us examine them more in detail.

Human capital refers to the human resource or personal dimension of the quality of teachers in the school - their basic teaching talents. We can define teachers' human capital as their set of knowledge and skills, the duration of their education/training path, their emotional intelligence, their empathy, and their ability to understand a heterogeneous student population[3]. Therefore, human capital refers to the knowledge and skills that every teacher must have in order to stimulate each student to achieve his/her learning and potential development in the best possible way [45]. For decades, it was thought that having good human capital was sufficient to be a good teacher: devotion, commitment, study, training, culture and substantial practice. However, in the teaching profession, human capital is not everything. Today, possessing the content to be taught, the didactic methods, as well as the consolidated practices to teach that content is no longer sufficient[12].

Hargreaves and Fullan [23] stressed two other types of capital in the teaching profession: social and decisional (or decisionmaking) capital. It is not the aim of this essay to review the main theoretical approaches on social capital [11], [44]. In the educational context, it refers to the construction of relationships based on trust and collaboration among teachers, teachers and managers, teachers and students, and teachers and parents, as well as among schools. Human and social capital are both important, but human capital is not as influential as social capital as a lead strategy [24]. Leana [28] found that teachers with low human capital who happened to work in a school with higher social capital achieved better outcomes than those in schools with lower social capital. Being in a school around others who are working effectively rubs off on teachers and engages them. Interpersonal trust and individual expertise work hand-in-hand toward better results. Social capital increases an individual's knowledge by providing access to other people's human capital [20].

Lastly, decisional capital refers to the sum of practice and expertise in making decisions disseminated to many individuals or groups in a school and its community. It refers to the resources of knowledge, intelligence and energy required to put human and social capital to work to achieve the school's goals [23]. It should be thought of at both the individual (i.e., a given teacher's expertise) and group levels (i.e., the collective judgement of two or more teachers, [20]) in making good decisions in complex circumstances. Among the three different types of capital identified by Hargreaves and Fullan [23], social capital is the most important. Since uncertainty and unpredictability are fundamental aspects in the educational practice, collaboration is essential because it is through interaction with colleagues that uncertainty can be managed.

Research on the power of collaborative cultures to achieve results, which has been accumulating for over 40 years, points to the power of social capital to improve student learning [30], [31]. Collaborative cultures accumulate and circulate knowledge, assistance and support, which helps teachers to become effective, increases their confidence and encourages them to be more open to and actively engaged in improvement and change. Collaborative cultures require attention to the structures and formal organization of school life. However, their underlying sources of strength are informal, namely relationships, conversations, expressions of interest andthe provision of support [23].

Thus, the issue of collaborative cultures is apparently becoming increasingly important in teachers' professionalism. Here, the focus will be on the potential linkages between the diffusion of digital technologies in schools and teachers' collaboration practices, exploring the opportunities and shortcomings in the development of teachers' professional 
communities and the role played by digital technologies in fostering them.

\section{Teachers' collaboration, professional communities and networks of relationships}

The focus here is on the so-called "organizational" innovation based on the definition of different types of innovation contextualized within the education sector [34]. Organizational innovation refers to the introduction of significant new organizational structures and organizational methods in workplace organization or external relations. In the education sector, organizational innovations could be, for example, the employment of new ways of organizing the work among teachers or organizational changes in the administrative area [36]. Based on such definition, it is interesting to inquire whether, and to what extent, the widespread diffusion of digital technologies in schools is changing teachers' working practices, particularly their collaborative cultures, the professional communities arising on the web and the social relations (in person as well as virtual) among their members.

A first aspect emerging from the research in this field is that the introduction of a technology seems to "force" teachers to activate networks of relationships [43]. Indeed, "social relations" have a key role in promoting technology in schools [16].

Here, we will just briefly refer to the two factors emerging from the literature, mainly affecting the differences identified in the collaborative behaviors of teachers. According to the Capability Approach, the relation existing between the possession of a "good" (e.g. access to an e-learning environment or to a social network site) and the functioning to achieve certain beings and doings (e.g. to achieve high-quality learning or establish a significant relation) is influenced by two main types of conversion factors. First, among the personal conversion factors, age and familiarity with digital technologies have emerged as the most relevant. These are two strictly related variables, because, generally, younger teachers show higher levels of familiarity with the use of ICTs. However, a direct correlation between the two variables should not be taken for granted. As Hargreaves and Fullan [23] showed, the stereotype is that teachers who are late in their careers are resisters. However, four types of teachers can be identified. First are the renewed teachers, who are constantly learning and being challenged. Disenchanted teachers were once very excited about change but, as a result of negative experiences, have become discouraged; however, they can be re-enchanted. Then, there are the quiet teachers. Introverts are more likely to work with two or three people rather than the entire school to make improvements, and that is the best way to work with them. The fourth group is the resisters. These are the educators on whom those who run performance evaluations have focused, i.e., they are the deadwood that should be removed.
With reference to the environmental conversion factors, the contextual conditions in which teachers work clearly emerges as key elements in impacting the teachers' digital capabilities development. We refer particularly to the quality and quantity of the ICT equipment available in schools, the opportunity to connect to the Internet, the greater or lesser willingness of a school's head, the more or less positive relationships among the staff, the different "climate" of each institution, etc. Considering, for example, the size of schools, the evidence of its influence in fostering the adoption and diffusion of digital technologies among teachers is not unanimous. Indeed, in small educational institutions, there is a greater propensity to disseminate ICTs than in medium or large schools, as the intense social relationships and collegiality seem to influence the attitudes of the teachers [60]. Nevertheless, other research has considered school-related factors as less influential [19], instead highlighting the greater importance of personal factors.

The consideration of both personal and contextual conversion factors reveals significant differences not only at the national level (among regions and cities), but also among schools (within the same region or the same city) and among classes within the same school. This leads to an investigation of the potential emergence of new forms of inequality in schools, linked to the diffusion of digital technologies involving both teachers and students.

\section{FINDINGS}

Nowadays, "digital skills" is one of the main areas of teachers' professional development, indicating the most useful skills for teachers in today's schools. The question to ask is the following: which capital and which capabilities should be fostered? Here, the focus will be on two aspects that are more related to the issues tackled in the article. The first refers to the creation of networks of schools. The second is the enhancement of a training model based on experiential training among colleagues.

For the first aspect, the underlying assumption is that a school that builds networks and relationships is best rooted in the context in which it operates. Both Bryk et al. [8] and Leithwood [29] showed that developing the social capital of schools and of the community creates a powerful combination. When schools work on their social capital, they are more likely to see parents and the community as part of the solution. When they remain isolated, individualistic cultures, they can easily treat parents as part of the problem, reinforcing a downward spiral. According to [24], the best way to support and motivate teachers is to create conditions in which they can together be effective day after day. This does not mean intra-school collaboration alone; it should also include inter-school and inter-district collaboration.

The activity most frequently conducted by networks of schools relates to teachers' training and professional development; within the network, the so-called hub school has the task of managing, from an administrative and practical 
point of view, the training activities for the teaching staff of the different schools in the network. This could be an effective way to foster the development of collaborations among schools and to start co-planning projects that benefit all the stakeholders involved.

The second aspect to be underlined refers to the enhancement of a teacher training model that is carried out from a practicalcritical perspective, with practical activities prevailing over exclusively theoretical ones. This is particularly interesting in relation to digital technology training, in which the experiential and practical aspects are very important for the dissemination of a multimedia culture within schools that could be conveyed by more experienced teachers to less experienced colleagues. This refers to the socialization and sharing of knowledge and skills within the school; the focus is on the social capital of teachers, as well as that of the schools.

Drawing on international experiences[59], [57], some of the lessons learned can be outlined, providing recommendations for policy interventions. Among these, the UOC report [59] mentions the accreditation of voluntary training and other teacher professional development activities (e.g. participation in projects, collaboration and networking, self-training). Moreover, active engagement with informal networks and communities of practice focused on technology and education is also helpful. Informal exchange and collaboration between teachers, or together with other practitioners, is fruitful for the development of technological awareness and practical knowledge. The construction of networks of practitioners depends on a proactive attitude towards networking and collaboration among teaching staff and other practitioners interested in promoting sustainable, comprehensive, multistakeholder approaches to technological pedagogy. The sustainability of such networks relies on active collaboration between teachers. Therefore, teachers should also be prepared to share knowledge and experience related to technology among themselves, which points to the importance of abilities such as the capacity to design training sessions [59].

Recently, a growing interest in the design of learning spaces that support and facilitate collaborative learning - often underpinned with digital technologies - has been observed. The final report on the CAPITAL project (Curriculum and Pedagogy in Technology Assisted Learning) in England [32] showed a growing trend whereby employers were augmenting or replacing traditional Continuing Professional Development strategies with social networking tools to facilitate collaboration amongst employees [41]. On an international scale, eTwinning, part of the Erasmus+ program, provides a forum in which all those working in schools, including teachers, headteachers and librarians, can collaborate, develop projects and participate in an international community of practice[2]. Cooperation is encouraged at the levels of both school and individual teachers. eTwinning now has over 500,000 registered users, and involves nearly 180,000 schools[17]. At the same time, however, previous research illustrated the apparent increasing devolution of power to individual schools and new federations that may bring schools together under a single sponsor while remaining geographically dispersed. This may mean an increased role for technology-supported inter-institutional collaboration amongst teachers [32]. Indeed, strong support for peer-to-peer learning as an expanding force in teachers' professional development is observed. This should form part of a blended approach in which more informal, socially networked learning is merged with formal training. As shown by the UNESCO report [57] looking at the conditions impacting the development of digital skills based on five international comparative surveys, Hong Kong has developed an ICT training framework for teachers, aiming at increasing their career development opportunities in the digital field. It promotes the creation of communities of practice among teachers to disseminate new skills and pedagogical methods, covering both teachers' initial training and their continuing training, adapting to the specific requirements of pre-school, primary and secondary education. Teacher social and professional networks can support collective learning and innovation, and help to address the risk of professional isolation among individual teachers [17].

\section{DISCUSSION}

Policy implications on teachers' professional development: the added value of (technology supported) peer-to-peer learning

The article has tackled some issues that have several policy implications.

A first aspect refers to both the pre-service and the in-service training of teachers. The TALIS survey adopted a broad definition of professional development among teachers [36], as activities that develop an individual's skills, knowledge, expertise and other characteristics as a teacher. The definition recognizes that development can be provided in many ways, ranging from the formal to the informal. It can be made available through external expertise in the form of courses, workshops or formal qualification programs, through collaboration between schools or between teachers across schools (e.g. observational visits to other schools or teacher networks) or within the schools in which the teachers work. In this last case, development can be provided through coaching/mentoring, collaborative planning and teaching, and the sharing of good practices [36]. However, most of the strategies recently developed in terms of teachers' training seem to be characterized by a marked individualism, and little space is dedicated to collaboration between colleagues. Thus, the development of social capital is not currently a widelyused strategy in the teaching profession [23]. Further, collaboration among teachers does not play an important role in training initiatives for teachers [45].

Generally, policymakers think almost exclusively of professional learning as individual learning. In contrast, the focus should be on creating "social learning" [40]. Investment in collective development is the key to more rapid and deep improvement. For this reason, the policies and corresponding 
strategies must invest in purposeful group learning and development [21]. From a policy perspective, effective teacher collaboration can be stimulated in a number of ways, including the following ([21]: by creating incentives for schools to establish flexible structures within the school day and year, allocating time for teachers and leaders to participate in collegial planning, job-embedded professional learning opportunities, and collaboration focused on the analysis of evidence of student learning and the development of focused strategies for improvement; by enabling teachers working across schools to develop more of the curriculum together - investing in their professional capital, and especially social capital, as they jointly create high-quality curriculum units of study. Teachers do not learn these practices once and for all (and in some cases, they do not learn them at all) in pre-service teacher education programs. They learn them most effectively through their practice on the job and by having access to coaches and skilled peers [20].

Technology per se does not add any real value to education, as the evaluation of many policies and school interventions has shown [18], [57]. The matter of evaluation requires careful attention to identify what and how to evaluate. Contributors to the CAPITAL project's Innovation Forums expressed concern about the need to be clearer that 'what works' is more important than 'what is new'.

\section{CONCLUSION}

We conclude by providing some remarks on the helpfulness of adopting the Capability Approach to examine issues discussed in this article, highlighting two main points. The first refers to the need for a multidimensional approach to take into account the importance of the different levels of analysis and their interconnections. The Capability Approach represents an added value, because, often, the relationships between ICTs and educational processes and practices are examined only on one level (macro, meso, micro, input, process, outcome / impacts). Thus, the investigations are very limited, underestimating the complexity of the phenomena under examination and allowing light to be shed only on certain parts of them. A multidimensional approach instead allows the clarification of how the different aspects are interconnected and the links among the parts of an increasingly complex scenario. In addition, it reduces the risk of conclusions that, in the past, have often proven to be reductive, simplistic and/or disconnected from the concrete contexts.

Secondly, the importance that the Capability Approach assigns to the context is noteworthy. According to the Senian framework, it plays a decisive role in influencing individual opportunities to transform resources into functioning, thus allowing subjects to do and be what they value. The assessment of teachers' capabilities cannot be achieved independently of the context, but instead requires in-situ contextualized judgements [5], [6]. Thus, by acknowledging the conversion factors, the Capability Approach takes into account the broader social and institutional context that affects a person's capability set and recognizes that our opportunities and prospects depend crucially on what institutions exist and how they function [54].

To conclude, the Capability Approach focuses our attention on the ways in which the potential for capital accumulation through capability acquisition could be frustrated by structural and sometimes policy-based obstacles to opportunity[4]. It stresses the interdependence of the various types of capital and functioning in the different domains of life [26]. Accordingly, the question arises of whether and how policies can be tools aimed at providing the subjects with the resources necessary to develop an individual self-realization project and enabling them to identify different available opportunities and to choose among the possible alternatives [54].

\section{REFERENCES}

[1] Argentin, G. (2018). Gli insegnanti nella scuola italiana. Bologna: Il Mulino.

[2] Bauman, Z. (2001). Voglia di Comunità. Bari: Laterza.

[3] Becker, G. S. (1964). Human capital. New York: Columbia University Press.

[4] Bonvin, J. M., \& Farvaque, N. (2005), What Informational Basis for Assessing Job-Seekers?Capabilities vs. Preferences. Review of Social Economy, 63(2), 269-289.

[5] Bonvin, J. M., \& Orton, M. (2009). Activation policies and organizational innovation: The added value of the capability approach. International Journal of Sociology and Social Policy, 29(11), 565-574.

[6] Bonvin, J. M., \& Thelen, L. (2003). Deliberative democracy and capabilities. The impact and significance of capability for voice. Presented at the 3rd Conference on Capability Approach, Pavia, Italy.

[7] Bourdieu, P. (1986). The forms of capital. In J. Richardson (Ed.), Handbook of theory and research for the sociology of education (pp. 241-258). New York: Greenwood.

[8] Bryk, A., Sebring, P., Allensworth, E., Luppescu, S., \& Easton, J. (2010). Organizing schools for improvement: Lessons to the common core: Ensuring equity through professional learning. Thousand Oaks, CA: Corwin.

[9] Castells, M. (1996). The information age: Economy, society and culture. vol. 1: The rise of the network society. Oxford: Blackwell.

[10] Chiappero-Martinetti, E., \& Sabadash, A. (2014). Integrating human capital and human capabilities in understanding the value of education. In S. Ibrahim \& M. Tiwari (Eds.), The capability approach. From theory to practice (pp. 206-230). London: Palgrave Macmillan.

[11] Coleman, J. S. (1990). Foundations of social theory. Cambridge: Harvard University Press.

[12] Colombo, M. (2017). Gli insegnanti in Italia. Radiografia di una professione. Milano: Vita \& Pensiero.

[13] Colombo, M., \& Landri, P. (2009). Schools and networked sociality. The making of new technologies for teaching-andlearning. Italian Journal of Sociology of Education, 1(1), 97-103.

[14] Curran, J. (2012). Rethinking internet history. In J. Curran, N. Fenton \& D. Freedman (Eds.), Misunderstanding the internet (pp.34-65). London: Routledge.

[15] Delbono, F., \& Lanzi, D. (2007). Povertà, di che cosa? Risorse, opportunità, capacità. Bologna: il Mulino.

[16] Drent, M., \& Meelissen, M. (2008). Which factors obstruct or stimulate teacher educators to use ICT innovatively? Computers and Education, 51, 187-199.

[17] European Commission (2018). Networks for learning and development across school education. Bruxelles: European Commission:

[18] European Commission (2020). Digital Education Action Plan. EC: Bruxelles. 
[19] Frank, K. A., Zhao, Y., \& Borman, K. (2004). Social capital and the diffusion of innovations within organizations: Application to the implementation of computer technology in schools. Sociology of Education, 77(2), 148-171.

[20] Fullan, M. (2016). Amplify change with professional capital. Journal of Staff Development, 37(1), 44-56.

[21] Fullan, M., Rincón-Gallardo, S., \& Hargreaves, A. (2015). Professional capital as accountability. Education Policy Analysis Archives, 23(15).

[22] Hanushek, E.A., \&Woessmann, L. (2020). The Economic Impacts of Learning Losses. OECD: Paris.

[23] Hargreaves, A., \& Fullan, M. (2012). Professional capital. Transforming teaching in every school. London: Routledge.

[24] Hargreaves, A., \& Fullan, M. (2013). The power of professional capital. Journal of Staff Development, 34(3), 36-39.

[25] Hirschman, A.O. (1970). Exit, voice, and loyalty. Responses to decline in firms, organizations, and states. Cambridge: Harvard University Press.

[26] Lambert, M., Vero J., \& Zimmermann, B. (2012). Vocational training and professional development: A capability perspective. Continuing Professional Development, 16(3),164-182.

[27] Landri, P., \& Viteritti, A. (Eds.) (2016). Special issue sociomaterialità in educazione. Scuola Democratica, 1, 2016.

[28] Leana, C. (2011). The missing link in school reform. Stanford Social Innovation Review, 9(4), 30-35.

[29] Leithwood, K. (2011). Characteristics of high performing school districts in Ontario. Toronto, Ontario: OISE/ University of Toronto.

[30] Lieberman, A., \& Mace, D.P. (2010). Making practice public: Teacher learning in the 21st century. Journal of Teacher Education, 61(1-2), 77-89.

[31] Little, J.W. (1982). Norms of collegiality and experimentation: Workplace conditions of school success. American Educational Research Journal, 19(3), 325-340.

[32] Manches, A., Phillips, B., Crook, C., Chowcat, I., \& Sharples, M. (2010). CAPITAL-Curriculum and Pedagogy in Technology Assisted Learning. Hal- 00593082.

[33] Nussbaum, M. (2011). Creating capabilities. The human development approach. Boston: Harvard University Press.

[34] OECD (2005). Oslo manual. The measurement of scientific and technological activities. Guidelines for collecting and interpreting innovation data (3rd ed.). Paris: OECD Publishing.

[35] OECD (2008). Innovation: The OECD definition. Paris: OECD Publishing.

[36] OECD (2009). Creating effective teaching and learning environments: First result from TALIS. Paris: OECD Publishing.

[37] OECD (2020). OECD Digital Economy Outlook 2020. OECD: Paris.

[38] Otto, H.U., \& Ziegler, H. (2006). Capabilities and education. Social Work and Society, 4(2), 269-287.

[39] Pandolfini, V., \& Poli, S. (2015). Education as a capability for young adults' life trajectories: Some evidence from an Italian case study. Italian Journal of Sociology of Education, 7(2), 43-69.

[40] Pentlan, A. (2014). Social physics: How good ideas spread: The lessons from a new science. New York: The Penguin Press.
[41] Phillips, B. (2009). Trends Analysis (one of two). Capital Report. Retrieved $\quad 30 \quad$ September 2010, from http://www.lsri.nottingham.ac.uk/capital/Yr2/SummaryReports

[42] Pitzalis, M. (2016). The technological turn: Policies of innovation, politics and mobilisation. Italian Journal of Sociology of Education, 8(2), 11-27.

[43] Pitzalis, M., Porcu, M., De Feo, A., \& Giambona, F. (2016). Innovare a scuola. Insegnanti, studenti e tecnologie digitali. Bologna: Il Mulino.

[44] Putnam, R.D. (2000). Bowling alone: The collapse and revival of American community. New York: Simon \& Schuster.

[45] Qvortrup, L. (2013). L'insegnante oggi: obiettivi di apprendimento, capitale professionale e comunità professionali di apprendimento. Periodico della Divisione della scuola Ticinese, Dipartimento dell'educazione, della cultura e dello sport.

[46] Ragnedda, M. (2017). The third digital divide. A Weberian approach to digital inequalities. London: Routledge.

[47] Ragnedda, M. (2018). Il digital divide. Le disuguaglianze digitali e i suoi vari livelli d'analisi. Quaderni di teoria sociale, 1, 81-106.

[48] Robeyns, I. (2005). The capability approach: A theoretical survey. Journal of Human Development, 6, 93-114.

[49] Schleicher, A. (2020). The impact of covid-19 on education. Insights from education at a glance 2020. OECD: Paris.

[50] Selwyn, N. (2016). Is technology good for education? Toronto: Wiley.

[51] Sen, A. (1984). Goods and people in resources, values and development. Oxford: Blackwell.

[52] Sen, A. (1985). Well-being, agency and freedom. The Dewey lectures 1984. The Journal of Philosophy, LXXXII (4), 169-221.

[53] Sen, A. (1992). Inequality re-examined. Cambridge: Harvard University Press.

[54] Sen, A. (1999). Development as freedom. Oxford: Oxford University Press.

[55] Syed, P., \& Whiteley, P. (1997). Political capital formation among British party members. In J.W. van Deth (Ed.), Private groups and public life: social participation, voluntary associations and political involvement in representative democracies (127146). London: Routledge/ECPR Psychology Press.

[56] UNESCO (2002). Education for all. Is the world on track? Paris: EFA.

[57] UNESCO (2018). Building tomorrow's digital skills - what conclusions can we draw from international comparative indicators? Working paper on Education Policy n. 6. Paris: UNESCO.

[58] United Nations (2021). Digital Economy Report 2021. Crossborder data flows and development: For whom the data flow. New York: United Nations Publications.

[59] UOC (Universitat Oberta de Catalunya) (2016). Quality framework for integrating ICT in the teaching-learning process. National Report Spain. DECODE, Erasmus+, Bruxelles.

[60] Wu, H.K., Hsu, Y.S., \& Hwang, F.K. (2008). Factors affecting teachers' adoption of technology in classrooms: Does school size matter? International Journal of Science and Mathematics Education, 6(1), 63-85. 